Article

\title{
Optimization of Ultrasound-Assisted Extraction of Polyphenols from Myrtus communis L. Pericarp
}

\author{
Nadia Bouaoudia-Madi ${ }^{1}$, Lila Boulekbache-Makhlouf ${ }^{1, *}$, Khodir Madani ${ }^{1}$, Artur M.S. Silva ${ }^{2} \mathbb{D}_{\text {, }}$ \\ Sofiane Dairi ${ }^{1,3}$, Sonia Oukhmanou-Bensidhoum ${ }^{1}$ and Susana M. Cardoso ${ }^{2, *(D)}$ \\ 1 Laboratoire de Biomathématiques, Biophysique, Biochimie, et Scientométrie (L3BS), \\ Faculté des Sciences de la Natureet de la Vie, Université de Bejaia, 06000 Bejaia, Algeria \\ 2 QOPNA \& LAQV-REQUIMTE, Department of Chemistry, University of Aveiro, 3810-193 Aveiro, Portugal \\ 3 Faculté des Sciences de la Nature et de la Vie, Université de Jijel, 18000 Jijel, Algeria \\ * Correspondence: lilaboulekbachemakhlouf@yahoo.fr (L.B.-M.); susanacardoso@ua.pt (S.M.C.)
}

Received: 17 May 2019; Accepted: 26 June 2019; Published: 2 July 2019

check for updates

\begin{abstract}
Response surface methodology (RSM) was used to optimize the extraction of phenolics from pericap of Myrtus communis using ultrasound-assisted extraction (UAE). The results were compared with those obtained by microwave-assisted extraction (MAE) and conventional solvent extraction (CSE) methods. The individual compounds of the optimized extract obtained by UAE were identified by ultra-high-performance liquid chromatography coupled with diode array detection and electrospray ionization mass spectrometry (UHPLC-DAD-ESI-MS ${ }^{n}$ ). The yield of total phenolic compounds (TPC) was affected more significantly by ethanol concentration, irradiation time, liquid solvent-to-solid ratio $(p<0.0001)$ and amplitude $(p=0.0421)$ and optimal parameters conditions set by the RSM model were $70 \%(v / v), 7.5 \mathrm{~min}$ and $30 \%$, respectively. The experimental yield of TPC (241.66 $\pm 12.77 \mathrm{mg}$ gallic acid equivalent/g dry weight) confirmed the predicted value (235.52 $\pm 9.9 \mathrm{mg}$ gallic acid equivalent/g dry weight), allowing also to confirm the model validity. Under optimized conditions, UAE was more efficient than MAE and CSE in extracting antioxidants, which comprised mostly myricetin glycosides. Globally, the present work demonstrated that, compared to MAE and CSE, UAE is an efficient method for phenolic extraction from M. communis pericarp, enabling to reduce the working time and the solvent consumption.
\end{abstract}

Keywords: myrtle; ultrasound-assisted extraction; phenolic compounds; antioxidant capacity; liquid chromatography analysis; mass spectrometry

\section{Introduction}

The Myrtus genus, belonging to the Myrtaceae family, comprises about 50 species that are native of the Mediterranean basin. Among those, M. communis is an aromatic evergreen perennial sub-shrub (high: 1-3 m) with white flowers (blossoming time: June to July) and dark blue ripe berries [1]. It is native to Southern Europe, North Africa and West Asia and widespread in the Mediterranean region. Its fruits are consumed either raw or processed in diverse products such as canned fruits, yogurts, beverages, jams and jellies. In addition, there has been a growing interest in the use of berry extracts as ingredients in functional foods and dietary [2]. Volatile oils, tannins, anthocyanins, fatty acids, sugars, and organic acids such as citric and malic acids are important components of these fruits [3]. In general, myrtle berries are accepted as being rich in phenolic compounds, which in turn are associated to the fruits claimed health effects, including the prevention of degenerative diseases, such as cancer and cardiovascular diseases [4]. In fact, phenolic compounds are accepted as potent antioxidants due to their double bonds and hydroxyl groups, being capable of preventing the oxidation of free radicals that may damage physiological molecules cells, such as lipid proteins and DNA [5]. Many studies have 
shown a positive relationship between the phenolics content and the antioxidant capacity of fruits and vegetables [4-6]. Moreover, the regular consumption of fruits and vegetables is believed to prevent oxidative stress events and oxidative-stress related diseases [7-9].

Due to countless beneficial characteristics of phenolic compounds in human health, research has been intensified, aiming to find fruits, vegetables, plants, agricultural and agroindustrial residues as sources of these bioactive components. Obtaining such compounds often requires many long and costly steps, such as extraction, isolation and identification [5], and often result in thermal degradation of various bioactive constituents [6,7]. In this context, the development of new extraction methods is one of the major challenges in technological innovation towards the direction of "Green chemistry" $[8,9]$. Among them, ultrasound-assisted extraction (UAE) and microwave-assisted extraction (MAE) are particularly attractive because of their simplicity, low cost of equipment, efficiency in extracting analytes from different matrices and the requirement of low energy, reduced quantity of solvent and/or time consumption [10], compared to conventional extraction methods, which have several disadvantages, such as the use of volatile and hazardous solvents, the long extraction time and more recovery energy [11]. The enhancement of the extraction process by ultrasounds is attributed to the disruption of the cell walls, reduction of the particle size and the increased mass transfer of the cell content to the solvent, caused by the collapse of the bubbles produced by acoustic cavitation [8]. The processing parameters optimization and interpretation of experiments compared to others has been previously done through response surface methodology (RSM) [12]. This latter has been shown to be a powerful tool in optimizing experimental conditions (factors) to maximize the response. With the experimental results of a response surface design, a mathematical polynomial model, describing the relation between a response (dependent variable) and the considered factors (independent variable), is built. The mathematical model, usually a second-order polynomial model, can be visualized graphically by drawing 2D contour plots or 3D response surface plots [13]. The model allows determining the optimum value of the independent variables $\left(X_{i}\right)$, as well as those of the dependent ones $(Y)$.

Previous studies focusing on phenolic compounds and/or the antioxidant abilities of myrtle pericarp have been performed with extracts obtained by conventional methods [14-16], while, to our knowledge, there is no available information on the optimization of ultrasonic procedure for the extraction of phenolic compounds from this matrix, using a safer solvent such as ethanol, which is an organic solvent used in the food and pharmaceutical industries [17]. Therefore, the present study aimed at the optimization of UAE process parameters using RSM, including ethanol concentration, extraction time, irradiation amplitude and liquid-to-solid ratio, to maximize the content of the extracted phenolics. Levels of phenolic compounds and the antioxidant activity of pericarp M. communis extract obtained under the optimum setting parameters (UAE-OPT extract) were compared with those of extracts obtained by microwave-assisted extraction (MAE) and conventional solvent extraction (CSE) methods, using previously established conditions [18]. Then, the individual phenolic compounds present in the optimized extract obtained by UAE were identified by UHPLC-DAD-ESI-MS ${ }^{\text {. }}$

\section{Materials and Methods}

\subsection{Plant Material}

The fruits of M. communis were harvested from spontaneous plants in Adakar, Bejaia, located in the northeast of Algeria. The collected samples were identified by the Vegetable Ecological Laboratory of the Algiers University, Algeria and a voucher specimen was deposited at the Herbarium of Natural History Museum of Aix-en-Provence, France, under the voucher number D-PH-2013-37-12. Berries were washed and then dried in a static oven at $40{ }^{\circ} \mathrm{C}$ for one week. Pericarps were separated manually from seeds and further grounded in an electrical grinder (A11Basic, IKA, Retsch, Germany), which was then sieved to obtain a fine powder $(<250 \mu \mathrm{m})$. 


\subsection{Extraction of Phenolic Compounds}

\subsubsection{Ultrasound Extraction}

UAE was performed in an ultrasonic apparatus (Vibra cell, VCX 75115 PB, SERIAL No. 2012010971 MODEL CV 334, SONICS, Newtown, Connecticut, USA) with a working frequency fixed at $20 \mathrm{kHz}$. For extraction, $1 \mathrm{~g}$ of the pericarp powder was placed in a $250 \mathrm{~mL}$ amber glass bottle containing ethanol. The suspension was exposed to acoustic waves under distinct setting parameters (solvent concentration, irradiation time, ultrasound amplitude and solvent-to-solid ratio). The temperature was maintained constant by circulating external cold water and checking the temperature using a T-type thermocouple [5]. Indeed, ultrasound is considered a non-thermal technology, since it increases only the local temperature without affecting the surrounding environment [19]. After extraction, the solution was filtered through a sintered glass filter of porosity 2.

To determine the effect of ethanol concentration, irradiation time, ultrasound amplitude and solvent-to-solid ratio on the extraction yield of phenolic compounds from myrtle pericarp, RSM was applied with a Box-Behnken Design (BBD) [5]. This design resulted in the testing of four factors in a single block of 30 sets of test conditions (Table 1). The constant values for irradiation time, liquid-to-solid ratio and ethanol concentration in the UAE trials were $10 \mathrm{~min}, 50 \mathrm{~mL} / \mathrm{g}$ and 50\% $(v / v)$, respectively.

$$
Y=\beta_{0}+\sum_{i=0}^{k} \beta_{i} X_{i}+\sum_{i=1}^{k} \beta_{i i} X^{2}+\sum_{i>1}^{k} \beta_{i j} X_{i} X_{j}+E
$$

where $X_{i}, X_{j}, \ldots, X_{k}$ are the independent variables affecting the responses $Y$ (the yield of total phenolic compounds); $\beta_{i}, \beta_{i i}$ and $\beta_{i j}$ are the regression coefficients for linear, quadratic and interaction terms, respectively; and $\mathrm{k}$ is the number of variables.

The factor levels were coded as -1 (low), 0 (central point or middle) and 1 (high), respectively, according to Equation (2):

$$
X_{i}=\left(X_{i}-X_{0}\right) / \Delta X \ldots
$$

where $X_{i}$ is the coded value of the variable $X_{i} ; X_{0}$ is the value of $X$ at the center point; and $\Delta X$ is the step change.

\subsubsection{Microwave-Assisted Extraction}

Phenolic extracts were obtained using a domestic microwave oven (Samsung MW813ST, Kuala Lumpur, Malaysia) adapted by adding of a condenser [18]. The apparatus operated at a frequency of $2450 \mathrm{MHz}$ and a maximum output power of $1000 \mathrm{~W}$ with a $100 \mathrm{~W}$ increment. The size of the heating cavity was $37.5 \mathrm{~cm}(\mathrm{~L}) \times 22.5 \mathrm{~cm}(\mathrm{~W}) \times 38.6 \mathrm{~cm}(\mathrm{D})$. The applied extraction conditions corresponded to those previously optimized [18]. A volume of $32 \mathrm{~mL}$ of $42 \%$ ethanol concentration was added to $1 \mathrm{~g}$ of pericarp Myrtus powder in a flat-bottomed flask. The mixture was irradiated at $500 \mathrm{~W}$ for $62 \mathrm{~s}$. The resultant extract was then filtered through a sintered glass filter of porosity 2 and was stored at $4{ }^{\circ} \mathrm{C}$ until further analysis.

\subsubsection{Conventional Solvent Extraction}

Conventional solvent extract followed the procedure established by Dahmoune et al. [5]. One gram of myrtle powder was placed in a conical flask, and $50 \mathrm{~mL}$ of $50 \%(v / v)$ ethanol were added. After stirring for $2 \mathrm{~h}$, the mixture was filtered through a sintered glass filter of porosity 2 and the extract was stored at $4{ }^{\circ} \mathrm{C}$ until further use.

\subsection{Analytical Determinations}

\subsubsection{Total Phenolic and Flavonoid Contents}

The total phenolic content (TPC) of the UAE, MAE and CSE extracts was assessed according to the method of George et al. [20] and expressed as $\mathrm{mg}$ of gallic acid equivalent (GAE) per gram of 
myrtle pericarp powder on dry weight (DW) basis (mg GAE g $\left.{ }^{-1} \mathrm{DW}\right)$. The total flavonoid content was estimated by the aluminum trichloride method according to Quettier-Deleu et al. [21] and the results were expressed as mg of quercetin equivalent per $\mathrm{g}$ of myrtle pericarp powder, on a DW basis.

\subsubsection{Total Monomeric Anthocyanins and Condensed Tannin Contents}

Total monomeric anthocyanin content was determined by the $\mathrm{pH}$-differential method [22], and the results were expressed as mg cyanidin-3-O-glucoside equivalents per g of myrtle pericarp powder on a DW basis. The condensed tannin content was determined by the $\mathrm{HCl}-\mathrm{vanillin}$ method as described by Aidi Wannes et al. [23] and the results were expressed as mg catechin equivalents per $g$ of myrtle pericarp powder on DW basis.

\subsubsection{Antioxidant Activity}

The antioxidant activity of all samples was tested by using two different tests, namely 1,1-diphenyl2-picrylhydrazyl radical ( $\mathrm{DPPH} \bullet$ ) scavenging activity and reducing power methods [24]. $\mathrm{DPPH} \bullet$ solution $(60 \mu \mathrm{M})$ was prepared in absolute methanol and reaction was performed by the adding of $3 \mathrm{~mL}$ of this solution to $1 \mathrm{~mL}$ of the extracts, during $20 \mathrm{~min}$ at $37^{\circ} \mathrm{C}$ in the dark. Thereafter, the absorbance was measured at $515 \mathrm{~nm}$. The inhibition rate of the extracts was calculated according Equation (3).

$$
\% \text { Scavenging }=\frac{\left(A_{\text {control }}-A_{\text {extract }}\right)}{A_{\text {control }}} \times 100
$$

where $A_{\text {control }}$ is the absorbance of $\mathrm{DPPH} \bullet$ and distilled water $A_{\text {sample }}$ is the absorbance of $\mathrm{DPPH}^{\bullet}$ and sample extract. $\alpha$-tocopherol and BHA $(250 \mu \mathrm{g} / \mathrm{mL})$ were used as positive controls.

For reducing power assay, $1 \mathrm{~mL}$ of desired dilution was mixed with $2.5 \mathrm{~mL}$ of sodium phosphate buffer $(0.2 \mathrm{M}, \mathrm{pH} 6.6)$ and $2.5 \mathrm{~mL}$ of $1 \%(\mathrm{~m} / \mathrm{v})$ potassium ferricyanide $\left.\mathrm{K}_{3}\left[\mathrm{Fe}(\mathrm{CN})_{6}\right)\right]$, followed by incubation in a water bath at $50{ }^{\circ} \mathrm{C}$ for $20 \mathrm{~min}$ and the addition of $2.5 \mathrm{~mL}$ of $10 \%(\mathrm{~m} / \mathrm{v})$ trichloroacetic acid. At last, an aliquot of the resulting solution $(1 \mathrm{~mL})$ was added to $5 \mathrm{~mL}$ of distilled water and 1 $\mathrm{mL}$ of $0.1 \%(m / v)$ of $\mathrm{FeCl} 3 \cdot 6 \mathrm{H} 2 \mathrm{O}$. Note that this method estimates the ability to reduce $\mathrm{Fe}^{3+}$ to $\mathrm{Fe}^{2+}$. Antioxidant compounds present in the samples form a colored complex with potassium ferricyanide, trichloroacetic acid and ferric chloride, which is measured at $700 \mathrm{~nm}$.

\subsection{Identification of Phenolic Compounds by UHPLC-DAD-ESI-MS ${ }^{n}$}

The phenolic compounds of the UAE-OPT extract were characterized by UHPLC-DAD-ESI-MSn (DAD: diode array detector; ESI: electrospray ionization) analysis on an Ultimate 3000 (Dionex Co., USA) apparatus equipped with an ultimate 3000 Diode Array Detector (Dionex Co., San Jose, CA, USA) and coupled to a mass spectrometer. Analysis was run on a Hypersil Gold (Thermo Scientific, San Jose, CA, USA) C18 column (100 mm length; $2.1 \mathrm{~mm}$ i.d.; $1.9 \mu \mathrm{m}$ particle diameter, end-capped) and its temperature was maintained at $30^{\circ} \mathrm{C}$. The mobile phase was composed of (A) $0.1 \%$ of formic acid $(v / v)$ and acetonitrile (B). The solvent gradient started with $5 \%$ of Solvent B, reaching $40 \%$ at $14 \mathrm{~min}$ and $100 \%$ at $16 \mathrm{~min}$, followed by the return to the initial conditions. The flow rate was $0.1 \mathrm{~mL}$ $\mathrm{min}^{-1}$ and UV-Vis spectral data for all peaks were accumulated in the range 200-700 $\mathrm{nm}$ while the chromatographic profiles were recorded at 280,340 and $530 \mathrm{~nm}$.

The mass spectrometer consisted of a Thermo LTQ XL (Thermo Scientific, San Jose, CA, USA) ion trap MS (mass spectrometer) apparatus equipped with an ESI source, operating in negative and positive modes, under the pre-established conditions [25].

\subsection{Statistical Analysis}

Each extraction trial and all the analyses were carried out in three independent analysis performed in triplicate. The influence of individual factors on the TPC yield (single-factor experiment) was estimated by Analysis of Variance (ANOVA) and Tukey's post hoc test with a 95\% confidence level, 
while data obtained from the BBD and Central Composite Design (CCRD) trials were analyzed through ANOVA for the response variable to evaluate the model significance and suitability. Significant and highly significant levels were set for $p<0.05$ and $p<0.01$, respectively. The John's MacIntosh Product (Version 7.0, SAS, Cary, NC, USA) and Design-Expert (Trial version 10.0, SAS, Cary, NC, USA) software packages were used to construct the BBD and CCRD and to analyze all the results. Principal Component Analysis (PCA) was applied to detect the relationships between contents of phenolic compounds, flavonoids, anthocyanins, tannins, as well as antioxidant activity and their extraction methodologies i.e., UAE, MAE and CSE. All tests were done in triplicate.

\section{Results and Discussion}

\subsection{Optimization of UAE Conditions}

\subsubsection{Modeling and Fitting the Model Using RSM}

The experimental design and subsequent response allied to TPC are summarized in Table 1, with results from TPC recovery varying in the range of 79-235 mg GAE/g DW.

Table 1. Central composite design with the observed responses and predicted values for yield of total phenolic compounds of Myrtus communis pericarp using the UAE method.

\begin{tabular}{|c|c|c|c|c|c|}
\hline Run & $\begin{array}{l}X_{1} \text {-Ethanol } \\
(\%, v / v)\end{array}$ & $\begin{array}{l}X_{2} \text {-Irradiation Time } \\
(\mathrm{min})\end{array}$ & $\begin{array}{c}X_{3} \text {-Amplitude } \\
(\%)\end{array}$ & $\begin{array}{c}X_{4} \text {-Solvent-to Solid Ratio } \\
(\mathrm{mL} / \mathrm{g})\end{array}$ & $\begin{array}{c}\text { TPC Recovery } \\
\text { (mg GAE/g DW) }\end{array}$ \\
\hline 1 & 50 & 2.5 & 50 & 25 & $134.93 \pm 11.37$ \\
\hline 2 & 70 & 10 & 70 & 30 & $195.24 \pm 0.99$ \\
\hline 3 & 30 & 5 & 30 & 20 & $105.29 \pm 11.72$ \\
\hline 4 & 70 & 5 & 30 & 30 & $221.73 \pm 3.64$ \\
\hline 5 & 50 & 7.5 & 50 & 25 & $200.50 \pm 12.82$ \\
\hline 6 & 50 & 7.5 & 50 & 15 & $78.90 \pm 10.45$ \\
\hline 7 & 50 & 7.5 & 50 & 25 & $200.90 \pm 28.02$ \\
\hline 8 & 50 & 7.5 & 50 & 25 & $200.10 \pm 23.11$ \\
\hline 9 & 50 & 7.5 & 90 & 25 & $200.02 \pm 13.23$ \\
\hline 10 & 70 & 10 & 30 & 30 & $214.07 \pm 14.66$ \\
\hline 11 & 50 & 7.5 & 10 & 25 & $210.72 \pm 2.70$ \\
\hline 12 & 50 & 7.5 & 50 & 25 & $210.21 \pm 15.39$ \\
\hline 13 & 10 & 7.5 & 50 & 25 & $170.43 \pm 9.38$ \\
\hline 14 & 30 & 10 & 70 & 20 & $159.56 \pm 10.02$ \\
\hline 15 & 30 & 10 & 70 & 30 & $228.39 \pm 12.96$ \\
\hline 16 & 50 & 7.5 & 50 & 25 & $203.34 \pm 16.40$ \\
\hline 17 & 70 & 10 & 70 & 20 & $200.42 \pm 14.47$ \\
\hline 18 & 70 & 10 & 30 & 20 & $185.51 \pm 13.34$ \\
\hline 19 & 50 & 7.5 & 50 & 35 & $195.94 \pm 12.80$ \\
\hline 20 & 50 & 12.5 & 50 & 25 & $190.43 \pm 15.47$ \\
\hline 21 & 70 & 5 & 70 & 30 & $142.96 \pm 9.60$ \\
\hline 22 & 30 & 10 & 30 & 20 & $118.92 \pm 12.08$ \\
\hline 23 & 70 & 5 & 70 & 20 & $115.45 \pm 16.12$ \\
\hline 24 & 30 & 5 & 30 & 30 & $219.12 \pm 18.72$ \\
\hline 25 & 30 & 10 & 30 & 30 & $180.77 \pm 9.38$ \\
\hline 26 & 70 & 5 & 30 & 20 & $161.68 \pm 9.42$ \\
\hline 27 & 30 & 5 & 70 & 30 & $179.22 \pm 9.70$ \\
\hline 28 & 90 & 7.5 & 50 & 25 & $235.21 \pm 17.36$ \\
\hline 29 & 50 & 7.5 & 50 & 25 & $210.21 \pm 16.60$ \\
\hline 30 & 30 & 5 & 70 & 20 & $111.38 \pm 7.63$ \\
\hline
\end{tabular}

The least square technique was used to calculate the regression coefficients of the intercept, linear, quadratic, and interaction terms [26] (Table 2). Notably, the linear parameters, namely ethanol concentration, irradiation time and liquid-solid ratio $(p<0.0001)$, followed by amplitude $(p=0.0421)$ significantly affected the extraction content of phenolic compounds. The quadratic terms $X_{2}^{2}$ and 
$X_{4}^{2}$ were highly significant at the level $p<0.001$, while the $X_{1}^{2}$ and $X_{3}^{2}$ terms were insignificant $(p>0.05)$. Regarding TPC yield, the interaction of ethanol concentration with amplitude of ultrasound $\left(X_{1}-X_{3}\right)$ and with liquid to solid ratio $\left(X_{1}-X_{4}\right)$, and that of irradiation time amplitude of ultrasound $\left(X_{2}-X_{3}\right)$ were highly significant $(p<0.0001)$, followed by irradiation time with liquid-to-solid ratio $(p=0.0054)$, amplitude of ultrasound with liquid-to-solid ratio $(p<0.0094)$ and ethanol concentration with irradiation time $(p=0.0367)$. Those significant terms played a dominant role in myrtle pericarp extraction by ultrasound. Indeed, those significant terms played a dominant role in myrtle pericarp extraction by ultrasound. This is justified by the analyses of variance, as represented in Table 2, with significant $p$-values $(p<0.0001)$ for the linear parameters, namely ethanol concentration $\left(X_{1}\right)$, irradiation time $\left(X_{2}\right)$ and liquid-solid ratio $\left(X_{4}\right)$, the quadratic terms $X_{2}^{2}$ and $X_{4}{ }^{2}$, and the interaction terms $\left(X_{1}-X_{3}\right),\left(X_{1}-X_{4}\right)$ and $\left(X_{2}-X_{3}\right)$. However, insignificant $p$-values $(p>0.0001)$ were obtained for the third linear parameter, amplitude $\left(X_{3}\right)$, the quadratic terms $X_{1}{ }^{2}$ and $X_{3}{ }^{2}$ and the interaction terms $\left(X_{1}-X_{2}\right),\left(X_{2}-X_{4}\right)$ and $\left(X_{3}-X_{4}\right)$.

Table 2. Estimated regression coefficients for the quadratic polynomial model and analyzes of variance (ANOVA) for the experimental results.

\begin{tabular}{|c|c|c|c|c|c|c|}
\hline Parameters & $\begin{array}{c}\text { Estimated } \\
\text { Coefficients }\end{array}$ & $\begin{array}{l}\text { Standard } \\
\text { Error }\end{array}$ & $D^{a}$ & $\begin{array}{l}\text { Sum of } \\
\text { Squares }\end{array}$ & F Ratio ${ }^{b}$ & Prob $>$ F \\
\hline Model & & & 14 & 46971.996 & 43.8356 & $<0.0001$ \\
\hline $\begin{array}{l}\text { Intercept } \\
\text { Linear }\end{array}$ & 205.032 & 3.912523 & & & 52.40 & $<0.0001$ \\
\hline$X_{1}$-Ethanol & 10.99875 & 1.736676 & 1 & 2903.340 & 37.9327 & $<0.0001$ \\
\hline$X_{2}$-Time & 14.04375 & 1.736676 & 1 & 4733.446 & 61.8434 & $<0.0001$ \\
\hline$X_{3}$-Amplitude & -3.994583 & 1.736676 & 1 & 382.961 & 5.0035 & 0.0421 \\
\hline$X_{4}$-Ratio & 27.390417 & 1.736676 & 1 & 18005.638 & 235.2474 & $<0.0001$ \\
\hline \multicolumn{7}{|l|}{ Quadratic } \\
\hline$X_{1}^{2}$ & -1.526438 & 1.717541 & 1 & 60.454 & 0.7898 & 0.3892 \\
\hline$X_{2}^{2}$ & -11.56144 & 1.717541 & 1 & 3468.113 & 45.3116 & $<0.0001$ \\
\hline$X_{3}^{2}$ & -0.888938 & 1.717541 & 1 & 20.503 & 0.2679 & 0.6128 \\
\hline$X_{4}^{2}$ & -17.87644 & 1.717541 & 1 & 8291.469 & 108.3279 & $<0.0001$ \\
\hline \multicolumn{7}{|l|}{ Interaction } \\
\hline$X_{1}-X_{2}$ & 5.049375 & 2.187167 & 1 & 407.939 & 5.3298 & 0.0367 \\
\hline$X_{1}-X_{3}$ & -11.46062 & 2.187167 & 1 & 2101.535 & 27.4570 & $<0.0001$ \\
\hline$X_{1}-X_{4}$ & -12.58812 & 2.187167 & 1 & 2535.37 & 33.1252 & $<0.0001$ \\
\hline$X_{2}-X_{3}$ & 15.196875 & 2.187167 & 1 & 3695.120 & 48.2775 & $<0.0001$ \\
\hline$X_{2}-X_{4}$ & -7.198125 & 2.187167 & 1 & 829.008 & 10.8312 & 0.0054 \\
\hline$X_{3}-X_{4}$ & -6.580625 & 2.187167 & 1 & 692.874 & 9.0525 & 0.0094 \\
\hline Lack of fit & & & 10 & 94.0987 & 4.550 & 0.0911 \\
\hline Pure error & & & 4 & & & \\
\hline$R^{2}$ & & & & & 0.9776 & \\
\hline Adjusted $R^{2}$ & & & & & 0.9553 & \\
\hline C.V. $\%$ & $3.71 \%$. & & & & & \\
\hline RMSE & 8.7186 & & & & & \\
\hline CorTotal $^{\mathrm{c}}$ & & & 28 & 48043.545 & & \\
\hline
\end{tabular}

\footnotetext{
${ }^{a}$ Degree of freedom; ${ }^{b}$ the model mean square to error mean square ratio; ${ }^{c}$ corrected total. DF, degree of freedom;
} F Ratio, freedom ratio; Prob, probability; C.V., coefficient of variation.

Based on the significant terms, the regression equation for the UAE efficiency was obtained as follows:

$$
\begin{gathered}
Y=205.032+10.998 X_{1}+14.043 X_{2}-3.994 X_{3}+27.390 X_{4}+5.049 X_{1} X_{2}-11.460 X_{1} X_{3}- \\
10.588 X_{1} X_{4}+15.196 X_{2} X_{3}-7.198 X_{2} X_{4}-6.580 X_{3} X_{4}-1.526 X_{1}^{2}-11.561 X_{2}^{2}-0.888 X_{3}^{2}- \\
17.876 X_{4}^{2}
\end{gathered}
$$

Note that the $p$-value can be employed to check the interaction strength between independent factors. From this analysis, $p$-value $<0.0001$ indicated that the response surface quadratic model was 
significant, which means that the model represented the data satisfactorily. The adjusted coefficient of determination ( $R^{2}$ adj) and the coefficient of determination $\left(R^{2}\right)$ were 0.9553 and 0.9776 , respectively, which implied that the sample variations of $97.76 \%$ for the UAE efficiency of myrtle pericarp phenols were attributed to the independent variables, and only $2.24 \%$ of the total variations could not be explained by the model, indicating a good degree of correlation between experimental and predict values of the TPC yield. In addition, the low value of coefficient of variance $(3.71 \%)$ clearly indicated that the model was reproducible and reliable [27]. All these results indicate that the model could work well for the prediction of TPC in the myrtle pericarp extracts.

\subsubsection{Response Surface Analysis (RSA)}

To provide a better understanding of the interaction between factors, the 3D response surface plot was constructed (Figure 1) using Equation (4). The graphs were generated by plotting the response using the z-axis against two independent variables, while keeping the other independent variable at the fixed level. Figure $1 \mathrm{~A}-\mathrm{C}$ shows the interactions between the ethanol concentration and each of the three other factors, namely irradiation time, amplitude and liquid-to-solid ratio, respectively, on the recovery of TPC. As shown, an increase of ethanol concentration from $20 \%$ to $80 \%(v / v)$, or extraction time from 5 to $10 \mathrm{~min}$ resulted in a rapid enhancement of TPC with a maximum of $235.21 \mathrm{mg} \mathrm{GAE} / \mathrm{g}$ being recovered with an irradiation time of $7.5 \mathrm{~min}$ and ethanol concentration of $70 \%(v / v)$.

The high phenolic content indicates that the mixture ethanol/water at $70 \%(v / v)$ allowed the solubilization of phenolics from $M$. communis pericarp, thus confirming the results of the single factor experiments [28] that explained the efficiency of the ultrasonic method by the fact that sonication improved the hydration and fragmentation process and hence facilitates the mass transfer of solutes to the extraction solvent. For the extraction yield of TPC performed at fixed extraction time and liquid-to-solid ratio, with varying ethanol concentration and amplitude (Figure 1B), it was possible to conclude that maximum recovery $(210.05 \mathrm{mg} \mathrm{GAE} / \mathrm{g}$ ) was achieved for $70 \%$ (v:v) of ethanol and an ultrasound amplitude of $35 \%$. This fact can be explained by the larger amplitude ultrasonic wave that promotes the liquid medium to produce more cavitation bubbles, thus resulting in a stronger pressure, capable of destroying the cell wall and accelerating mass transfer [29]. Figure 1C shows an enhancement of TPC that reached a peak value of $230.15 \mathrm{mg} \mathrm{GAE} / \mathrm{g}$, for $70 \%$ (v:v) ethanol and about $30 \mathrm{~mL} / \mathrm{g}$ of liquid-to-solid ratio. A higher ratio corresponds to a greater concentration difference between the exterior solvent and the interior tissues of Myrtus pericarp. It prominently prompted the TPC to be rapidly dissolved, which resulted in an increase in the extraction yield. The response surface plot for the significative interactive effect of irradiation time and amplitude of ultrasound on the response value at a fixed ethanol concentration and liquid-to-solid ratio is shown in Figure 1D. A higher TPC was obtained with the irradiation time at $10 \mathrm{~min}$ and amplitude of $30 \%$; these results confirm those reported in the literature [30,31]. Figure 1E shows an interaction between extraction time and the liquid-to-solid ratio $(p<0.05)$. The best content $(148 \mathrm{mg} \mathrm{GAE} / \mathrm{g})$ was found with the solid-liquid ratio of about $30 \mathrm{~mL} / \mathrm{g}$ and the radiation time of $10 \mathrm{~min}$. The increase of the ethanol proportion required high sonication intensity to generate the cavitation bubbles. However, a higher increase in the liquid-to-solid ratio diminished the supply of ultrasonic energy density and negatively affected the extraction yield.

The yield of TPC constantly improved with the increase of both amplitude of ultrasound and liquid-to-solid ratio, reaching a maximum when $X_{3}$ and $X_{4}$ became $32 \%$ and $20 \%(v / v)$, respectively (Figure 1F). Beyond this level, the yield of TPC reduced with the increase of $X_{1}$ and $X_{4}$. Hence, the interactive effect of $X_{3}$ and $X_{4}$ was remarkable. Overall, these results indicate that the TPC extraction yield was more significantly affected $(p<0.0001)$ by linear parameters, namely ethanol concentration, irradiation time and liquid-to-solid ratio. 

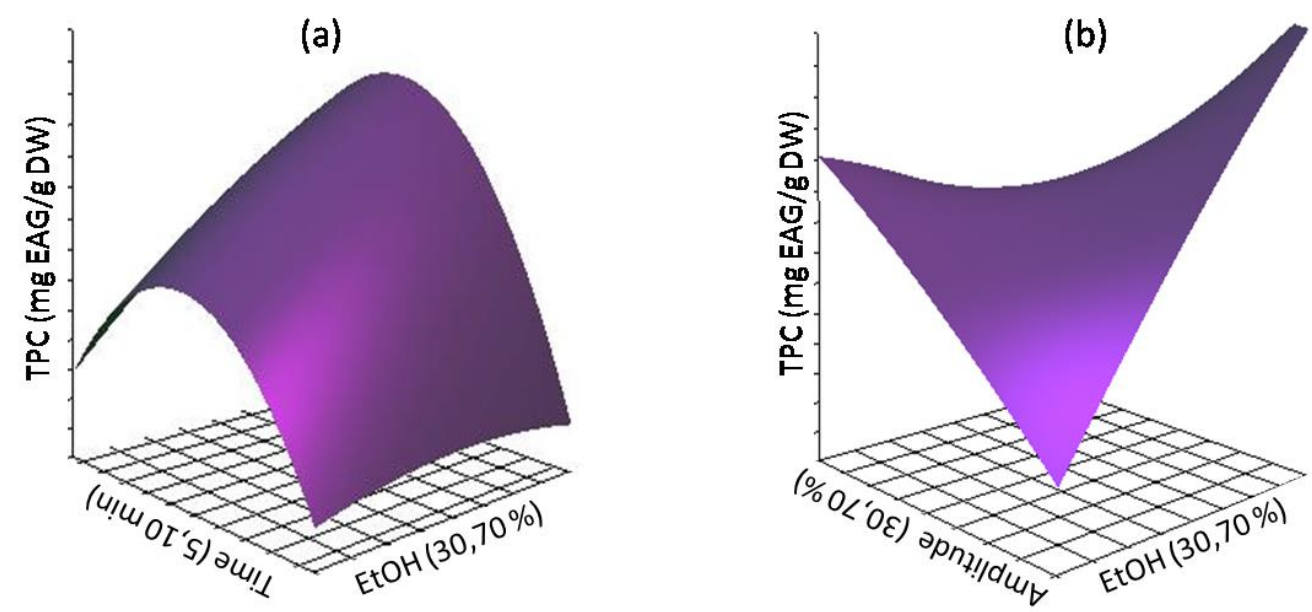

(c)

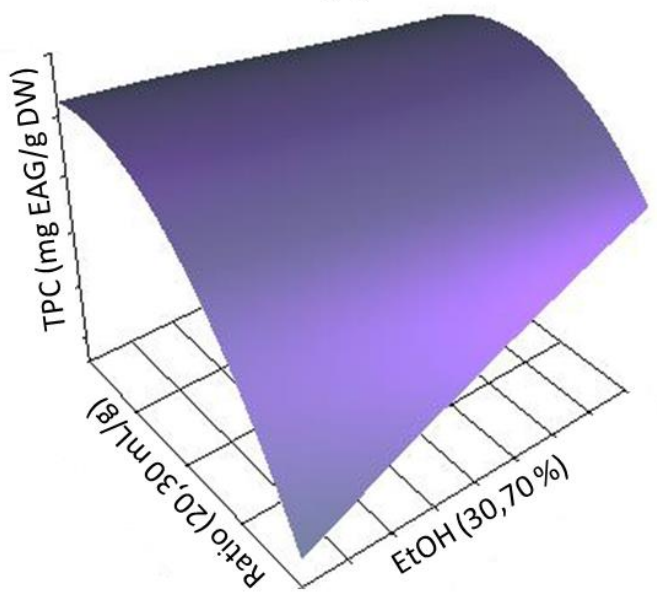

(d)

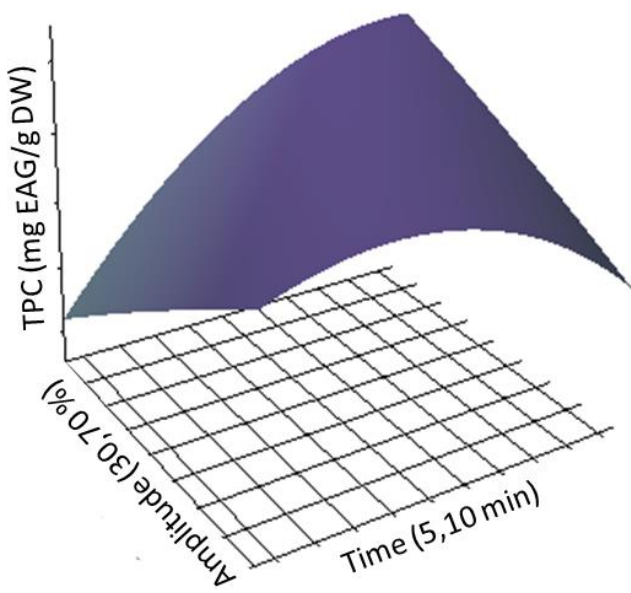

(e)

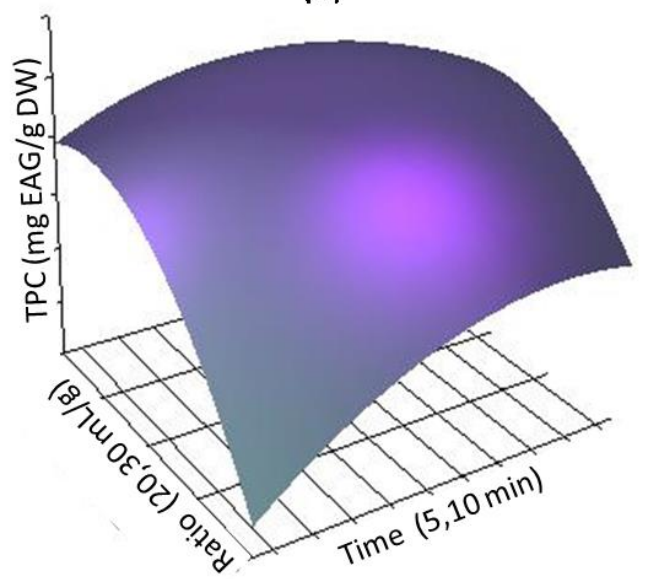

(f)

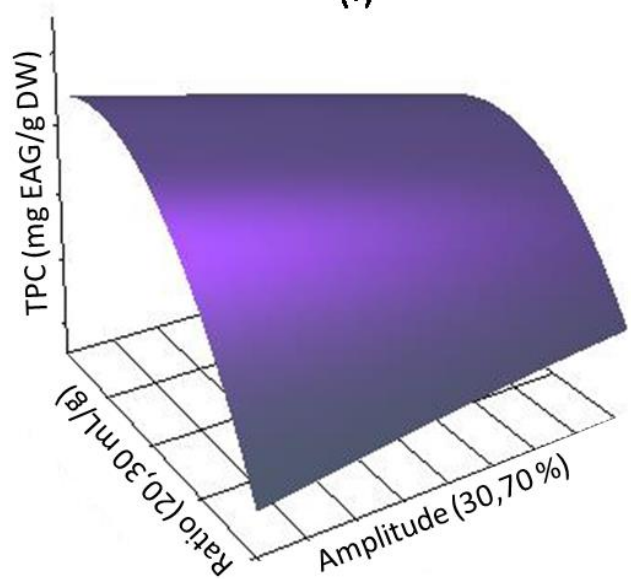

Figure 1. Response surface analysis for the Total phenolic compounds (TPC) with UAE with respect to: (a) ethanol concentration and irradiation time; (b) ethanol concentration and amplitude; (c) ethanol concentration and solvent-to-solid ratio; (d) extraction time and amplitude; (e) extraction time and solvent-to-solid ratio; and (f) amplitude and solvent-to-solid ratio. 


\subsubsection{Validation and Verification of the Predictive Model}

According to the result of response surface and prediction by this built model, the optimal conditions were thus obtained for the following conditions: ethanol at $70 \%(v / v), 7.5 \mathrm{~min}$ extraction time, $30 \%$ amplitude and a liquid-to-solid ratio of $28 \mathrm{~mL} / \mathrm{g}$. To ensure that the predicted result was not biased to the practical value, experimental rechecking was performed using these deduced optimal conditions. The predicted extraction yield of TPC in UAE-OPT was $235.52 \pm 9.9 \mathrm{mg} \mathrm{GAE} / \mathrm{g}$, that was consistent with the experimental yield of $241.66 \pm 12.77 \mathrm{mg} \mathrm{GAE} / \mathrm{g}$ DW (Table 3). The results showed no significant difference between the experimental and the predicted values. This strong correlation between experimental and the predicted values indicates that the response of regression model is adequate to reflect the expected optimization for the extraction of antioxidants from M. communis pericarp.

\subsection{Comparison between UAE, MAE and CSE Methods}

Remarkably, the highest TPC was obtained by UAE $(241.60 \pm 12.77 \mathrm{mg} \mathrm{GAE} / \mathrm{g})$. This corresponded to four and three times higher than that obtained by MAE and CSE, respectively, thus indicating that the application of UAE has a positive effect on the extraction of TPC (Table 3). The highest levels of TPC in UAE-OPT extract was reflected by its higher amounts of flavonoids, anthocyanins and tannins $(18.99 \pm 1.31 \mathrm{mg}$ QE/g; $25.06 \pm 0.36 \mathrm{mg} / \mathrm{g} ; 35.56 \pm 0.36 \mathrm{mg} \mathrm{CE} / \mathrm{g}$, respectively). These findings are consistent with those reported in the literature [32] and are mainly attributed to the fact that ultrasound radiation can facilitate mass transfer and accelerate the extracting process so that the extraction of bioactive compounds may be improved. Hence, according to the overall data, it is possible to conclude that the herein optimized UAE process yields higher levels of bioactive compounds in a short time and requires less solvent consumption than MAE and CSE. Note that, in this study, the operating temperature in the UAE-OPT was kept constant at room temperature, excluding any heating effect. This might positively or negatively influence the polyphenols recovery depending on the applied amplitude. 
Table 3. Comparison of extraction yield of polyphenols obtained by optimized ultrasound-assisted (UAE-OPT), microwave-assisted (MAE) and conventional solvent (CSE) methods.

\begin{tabular}{|c|c|c|c|c|c|c|c|c|c|c|}
\hline Method & $\begin{array}{c}\text { EtOH } \\
(\%)\end{array}$ & $\begin{array}{l}\text { Time } \\
(\mathrm{min})\end{array}$ & $\begin{array}{c}\text { US amp } \\
\text { (w/power) }\end{array}$ & $\begin{array}{l}\text { Liq:sol } \\
\text { (mL/g) }\end{array}$ & $\begin{array}{c}\text { TPC } \\
\text { (mg GAE/g) }\end{array}$ & $\begin{array}{c}\text { Flavonoids } \\
\text { (mgQE/g) }\end{array}$ & $\begin{array}{c}\text { Anthocyanin } \\
(\mathrm{mg} / \mathrm{g})\end{array}$ & $\begin{array}{c}\text { Tannins } \\
\text { (mg CE/g) }\end{array}$ & $\begin{array}{c}\text { DPPH } \\
(\%)\end{array}$ & $\begin{array}{c}R P \\
(\text { Abs 700 nm) }\end{array}$ \\
\hline UAE-OPT & 70 & 7.5 & 30 & 28 & $241.66 \pm 12.77^{a}$ & $18.99 \pm 1.31^{\mathrm{a}}$ & $25.06 \pm 0.36^{\mathrm{a}}$ & $35.56 \pm 0.36^{a}$ & $90.71 \pm 0.23^{a}$ & $0.568 \pm 0.002^{b}$ \\
\hline MAE & 42 & 62 & 500 & 32 & $119.59 \pm 8.40^{b}$ & $11.5 \pm 0.01^{b}$ & $5.64 \pm 0.06^{c}$ & $31.70 \pm 1.00^{b}$ & $87.16 \pm 0.28^{b}$ & $0.439 \pm 0.006^{b}$ \\
\hline CSE & 50 & 7200 & & 50 & $76.40 \pm 7.27^{c}$ & $6.95 \pm 0.20^{c}$ & $6.96 \pm 0.72^{b}$ & $30.70 \pm 0.17^{c}$ & $88.03 \pm 1.04^{b}$ & $0.429 \pm 0.001^{b}$ \\
\hline BHA & & & & & & & & & $26.98 \pm 0.69^{c}$ & $1.37 \pm 0.03^{a}$ \\
\hline$\alpha$-tocopherol & & & & & & & & & $17.17 \pm 0.4^{d}$ & $0.53 \pm 0.01 \mathrm{~b}$ \\
\hline
\end{tabular}

Contents of TPC, flavonoids, anthocyans and tannins are means \pm standard deviation. Different letters in the same row indicate significant differences $(p<0.05)$ according to the ANOVA test. BHA, butylated hydroxyanisole; CE, catechin equivalents; DPPH, 1,1-diphenyl-2-picrylhydrazyl radical; EtOH, ethanol; GAE, gallic acid equivalents; Liq:sol, liquid-to-solid ratio; QE, quercetin; RP, ferric reducing antioxidant power; US amp, ultrasound amplitude. 
The antioxidant capacity of the extracts was assessed by $\mathrm{DPPH}^{\bullet}$ scavenging and ferric reducing antioxidant power assays. The results show that UAE-OPT extract presented higher DPPH $\bullet^{\bullet}$ scavenging ability (90.71\% inhibition) when compared to CSE ( $88.03 \%$ inhibition) and MAE ( $87.16 \%$ inhibition) extracts. The same tendency was also observed for reducing power, since the absorbance at $700 \mathrm{~nm}$ for UAE-OPT extract was considerably higher than those obtained for MAE and CSE $(0.439 \pm 0.006$ and $0.429 \pm 0.01$, respectively). This means that UAE method is more efficient for the recovery of antioxidants than the herein tested microwave and conventional solvent extraction methods, a fact that is probably due to its superior richness in phenolic components, including flavonols [33] and as evidenced in the following section. This information was also confirmed by PCA analysis. PCA was applied to the extracts (UAE-OPT, MAE and SCE) for phenolic compounds (TPC, flavonoids, anthocyanins and tannins) and antioxidant activity, where the two chosen factors justified $100.0 \%$ of total variance. The resulting plots allowed selecting the better extraction method of different compounds of myrtle pericarp, and clearly divided the samples into three groups, depending on the extraction method (Figure 2). For PC1, which explains $95.91 \%$ of the total variance, the first group showed a positive correlation with PC1, thus confirming that UAE was the best extraction method for phenolic compounds with potent antioxidant activity. The highest correlation was found between antioxidant activity ( $\mathrm{DPPH}^{\bullet}$ and RP essay) and anthocyanins, hence suggesting that these compounds might have a key influence on the antioxidant capacity of the extracts. The best correlation between the MAE and TPC, flavonoids and tannins were observed in the second group. PC2 explains only better $4.09 \%$ of the experimental variability, which could essentially be associated to the CSE method and anthocyanins content (the third group).

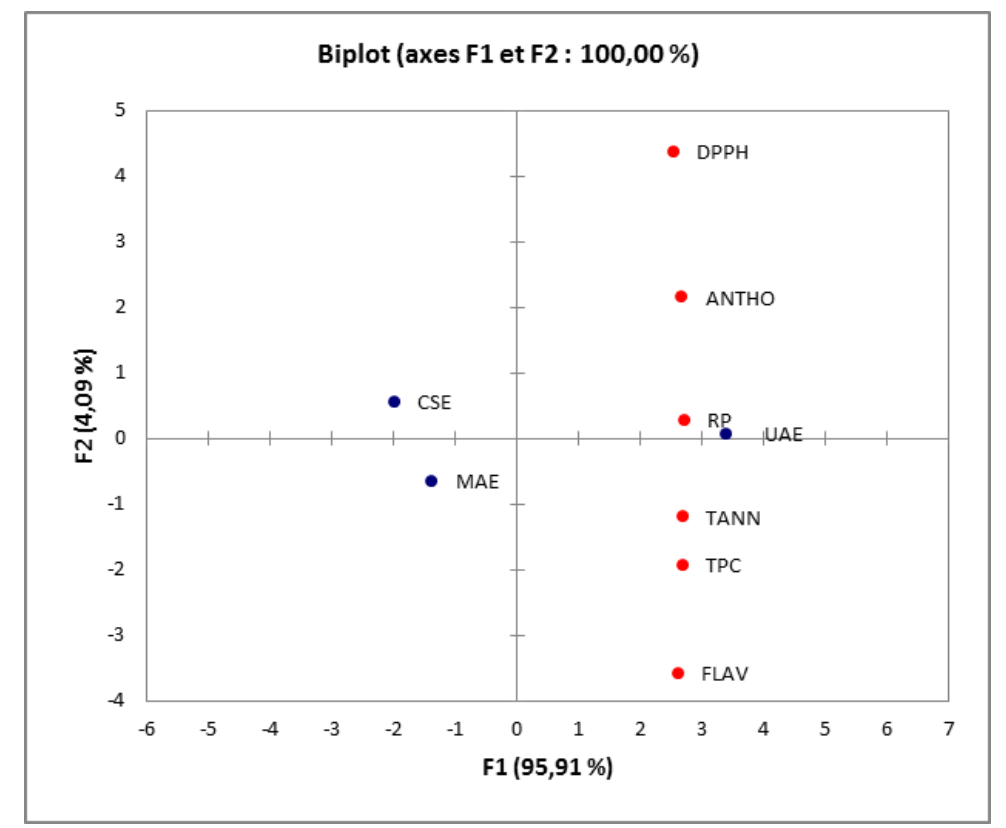

Figure 2. Principal component analysis of phenolic compounds for M. communis pericarp with UAE, MAE and CSE. FLAV, flavonoids; ANTHO, anthocyanins; TANN, tannins.

\subsection{Identification of Phenolics by UHPLC-DAD-ESI-MS ${ }^{n}$ Analysis}

The UAE-OPT extract was analyzed by UHPLC-DAD-ESI-MS ${ }^{n}$ to further elucidate its phenolic profile. The registered chromatogram at $280 \mathrm{~nm}$ is shown in Figure 3 and the UV-Vis and MS ${ }^{\mathrm{n}}$ spectral data of eluted peaks are summarized in Table 4. 


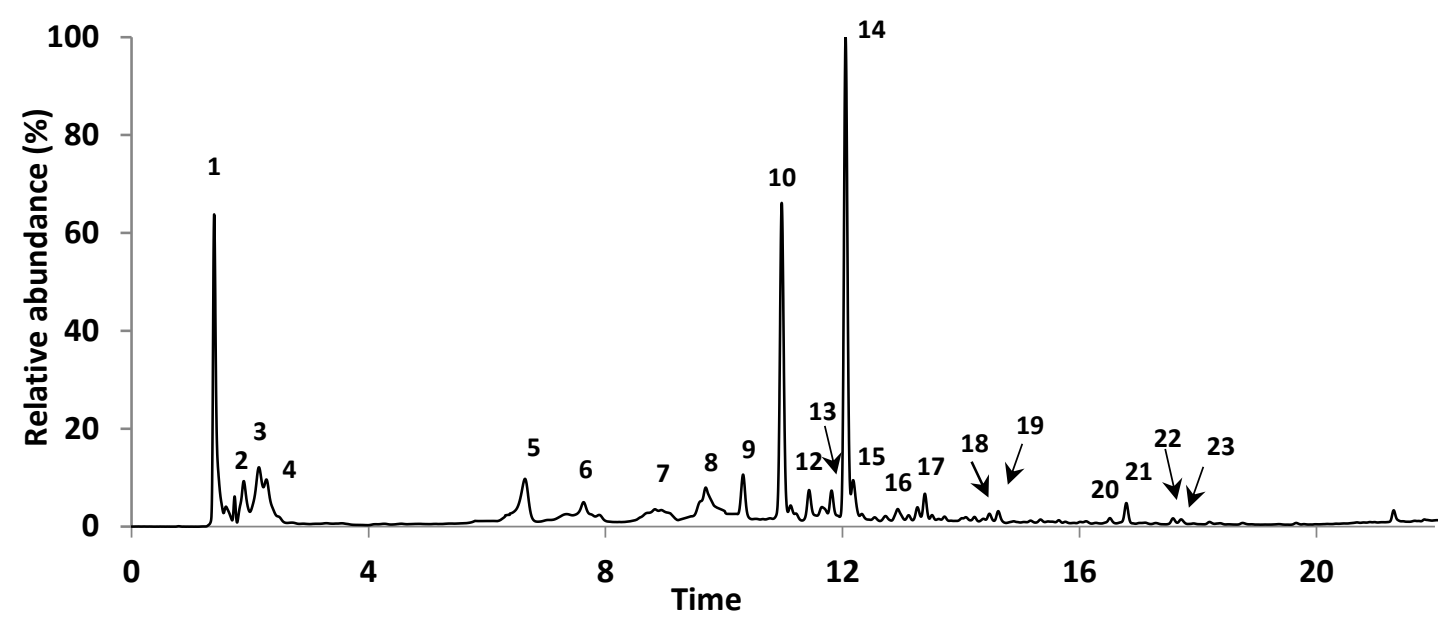

Figure 3. Chromatographic profile at $280 \mathrm{~nm}$ of $M$. communis pericarp extract obtained by UAE extraction at optimized conditions. Numbers in the figure correspond to the eluted UHPLC peaks for which UV and MS data are summarized in Table 4.

Among the distinct phenolic groups found in the extract, flavonols were the prevalent components. Overall, eleven flavonol glycosides were detected, being myricetin glycosides, namely myricetin-O-hexoside and myricetin-O-deoxyhexoside (eluted in Peaks 10/11 and 14/15, respectively) the major abundant ones, which probably correspond to myricetin-3-O-galactoside and myricetin-3-O-rhamnoside, since these are known to be present as main phenolic components in distinct organs of M. communis plant [34-38].

Besides the above compounds, four other myricetin glycosides were found in the extract. The compound eluted in Peak 9, showing a [M-H] ${ }^{-}$at $m / z$ 631, corresponded to myricetin-O-galloyl-hexoside, since the main fragments in $\mathrm{MS}^{2}$ spectrum were formed by the loss of $152 \mathrm{Da}$ (equivalent to a galloyl moiety) and $332 \mathrm{Da}$ (equivalent to the simultaneous loss of galloyl and hexosyl units). This could possibly correspond to myricetin 3-(6"-O-galloyl galactoside), which has been previously reported in leaves $[32,34,36,38]$ and berries [16]. In addition, the compounds with [M-H] ${ }^{-}$at $m / z 449$ (Peak 13) and at $m / z 625$ (co-eluted in Peak 18) were, respectively, assigned to myricetin-O-pentoside and myricetin-O-hexosyl-deoxyhexoside, according to their fragmentation pattern, which showed the loss of a pentosyl (132 Da) and deoxyhexosyl plus hexosyl (308 Da) moieties, respectively. In turn, the compound eluted in Peak 19 at $14.6 \mathrm{~min}$ with a pseudomolecular ion at $m / z 569$ and fragment ions at $\mathrm{m} / \mathrm{z} 485$ (equivalent to galloyl ester moiety) and 317 (myricetin) was tentatively assigned to a galloylester of myricetin.

The three remaining flavonols detected in the UAE-OPT extract were assigned to quercetin and kaempferol derivatives. From those, the compound eluted in Peak 12 was characterized by a $[\mathrm{M}-\mathrm{H}]^{-}$at $m / z 615$ and fragment ions at $m / z 463$ (-152 Da, loss of galloyl group) and 301 (-162 Da, loss of an hexosyl group), and was tentatively assigned to quercetin-O-hexoside-gallate on the basis of data reported in the literature [39-41]. This compound has been already reported in Myrtaceae family, namely in Eucalyptus species [42-44] and two other species from the same family, namely Myrcia multiflora extracts [45] and Eugenia edulis [46]. In addition, the compound eluted in Peak 17 with a deprotonated ion at $m / z 447$ and a base peak fragment ion at $m / z 301$ (-146, equivalent to the loss of a deoxyhexose unit), was identified as quercetin- $O$-deoxyhexoside according to literature data, probably corresponding to quercetin-3-O-rhamnoside [39,40]. This last flavonoid was previously detected in pericarp [29], berries [31,47] and leaves [30,31,35] of M. communis. Finally, the flavonol eluted in Peak $16\left([\mathrm{M}-\mathrm{H}]^{-}\right.$at $\left.\mathrm{m} / \mathrm{z} 447\right)$ presented the main fragment ion at $\mathrm{m} / \mathrm{z} 285$ in the $\mathrm{MS}^{2}$ spectrum, which in turn showed a fragmentation pattern coherent with kaempferol. Based on UV-Vis spectra $\left(\mathrm{UV}_{\max }\right.$ at 265 and 353) and $\mathrm{MS}^{\mathrm{n}}$ spectral data, this compound was assigned to kaempferol-O-hexoside. 
Table 4. UHPLC-DAD-ESI-MS ${ }^{\mathrm{n}}$ data for M. communis pericarp extract obtained under optimized UAE conditions.

\begin{tabular}{|c|c|c|c|c|c|}
\hline $\begin{array}{l}\text { No. } \\
\text { Peak }\end{array}$ & $\begin{array}{c}t_{R} \\
(\min )\end{array}$ & $\begin{array}{c}\lambda \max \\
(\mathrm{nm})\end{array}$ & $(m / z)$ & MS $^{n}$ Ions $(m / z)$ & Probable Compound \\
\hline \multirow{2}{*}{1} & \multirow{2}{*}{1.4} & \multirow{2}{*}{275} & $191^{\mathrm{a}}$ & $\mathrm{MS}^{2}[191]: 173,127,111,93$ & Quinic acid \\
\hline & & & $341^{\mathrm{a}}$ & $\mathrm{MS}^{2}[341]: 179$ & Caffeoyl-O-hexoside \\
\hline 2 & 1.9 & 276 & 331 & $\operatorname{MS}^{2}[331]: 271,169,241,211,193,125 ; \operatorname{MS}^{3}[271]: 211,169$ & Galloyl-O-hexoside \\
\hline 3 & 2.1 & 273 & 343 & $\operatorname{MS}^{2}[343]: 191,169,125$ & Galloyl quinic acid (isomer 1 ) \\
\hline 4 & 2.3 & 271 & 169 & $\operatorname{MS}^{2}[169]: 125$ & Gallic acid \\
\hline \multirow[t]{2}{*}{5} & 6.7 & 274 & 343 & $\operatorname{MS}^{2}[343]: 191,169,125$ & Galloyl quinic acid (isomer 2) \\
\hline & & 276,525 & $463^{\mathrm{a}, \mathrm{b}}$ & $\operatorname{MS}^{2}[463]: 301,300,337,315$ & Delphinidin-O-hexoside \\
\hline \multirow[t]{2}{*}{6} & 7.6 & & $495^{\mathrm{a}}$ & $\mathrm{MS}^{2}[495]: 343,325,191,169$ & Digalloyl quinic acid \\
\hline & & & $483^{\mathrm{a}}$ & $\operatorname{MS}^{2}[483]: 271,331,313,439,193,169 ; \operatorname{MS}^{3}[271]: 211,169$ & Digalloyl hexoside \\
\hline 7 & 8.8 & 274,525 & $477^{b}$ & $\operatorname{MS}^{2}$ [477]: 315,314 & Petunidin-O-hexoside \\
\hline \multirow[t]{2}{*}{8} & 9.7 & 274,525 & $647^{\mathrm{a}, \mathrm{b}}$ & $\mathrm{MS}^{2}[647]: 495,477$ & Petunidin-O-galloyl-hexoside derivative \\
\hline & & & $491^{\mathrm{a}, \mathrm{b}}$ & $\mathrm{MS}^{2}[491]: 329$ & Malvidin-O-hexoside \\
\hline 9 & 10.3 & 265,356 & 631 & $\operatorname{MS}^{2}[631]: 479,299,317$ & Myricetin-O-galloyl-hexoside \\
\hline 10 & 11.0 & 260,356 & 479 & $\mathrm{MS}^{2}[479]: 316,317$ & Myricetin-O-hexoside (isomer 1 ) \\
\hline 11 & 11.2 & 260,356 & 479 & $\mathrm{MS}^{2}[479]: 316,317$ & Myricetin-O- hexoside (isomer 2) \\
\hline 12 & 11.4 & 265,356 & 615 & $\operatorname{MS}^{2}[615]: 463,301 ; \operatorname{MS}^{2}[463]: 179,151$ & Quercetin $O$-hexoside- gallate \\
\hline 13 & 11.8 & 263,356 & 449 & $\operatorname{MS}^{2}[449]: 316,317$ & Myricetin-O-pentoside \\
\hline 14 & 12.1 & 261,351 & 463 & $\mathrm{MS}^{2}[463]: 316,317$ & Myricetin-O-deoxyhexoside (isomer 1) \\
\hline 15 & 12.2 & 261,351 & 463 & $\operatorname{MS}^{2}[463]: 316,317$ & Myricetin-O-deoxyhexoside (isomer 2) \\
\hline 16 & 12.9 & 265,353 & 447 & $\mathrm{MS}^{2}$ [447]: $285 ; \mathrm{MS}^{3}[285]: 267,257,241$ & Kaempferol-O-hexoside \\
\hline 17 & 13.4 & 257,350 & 447 & $\mathrm{MS}^{2}[447]: 301 ; \mathrm{MS}^{3}[301]: 179,151$ & Quercetin-O-eoxyhexoside \\
\hline \multirow{2}{*}{18} & \multirow{2}{*}{14.5} & \multirow{2}{*}{265,352} & $431^{\mathrm{a}}$ & $\operatorname{MS}^{2}$ [431]: $271 ; \operatorname{MS}^{3}[271]: 211,169$ & Galloyl derivative \\
\hline & & & $625^{\mathrm{a}}$ & $\operatorname{MS}^{2}$ [625]: 479,317 & Myricetin-O-hexosyl-deoxyhexoside \\
\hline 19 & 14.6 & 273,350 & 569 & $\mathrm{MS}^{2}[569]: 485,317$ & Myricetin-O-galloyl ester \\
\hline 20 & 16.5 & 276 & 583 & $\operatorname{MS}^{2}[583]: 271,565,313,211,331 ; \operatorname{MS}^{3}[271]: 211,169$ & Gallomyrtucommulone F \\
\hline 21 & 16.8 & 276 & 567 & $\operatorname{MS}^{2}$ [567]: $271,313,211,169 ; \mathrm{MS}^{3}$ [271]: 211, 169 & Gallomyrtucommulone C \\
\hline 22 & 17.6 & 276 & 467 & $\operatorname{MS}^{2}$ [467]: $271,313,169,211 ; \mathrm{MS}^{3}$ [271]: 211, 169 & Gallomyrtucommulone-type (isomer 1) \\
\hline 23 & 17.8 & 276 & 467 & $\operatorname{MS}^{2}$ [467]: $271,313,169,211 ; \mathrm{MS}^{3}$ [271]: 211, 169 & Gallomyrtucommulone-type (isomer 2) \\
\hline
\end{tabular}

Peak numbers correspond to those depicted in Figure $3 ;^{\mathrm{a}}$ co-eluted compounds in a peak fraction; ${ }^{\mathrm{b}}$ the respective $[\mathrm{M}]^{+}$ions were registered in the positive mode. $\mathrm{t}_{\mathrm{R}}$, retention time; $\lambda \mathrm{max}_{,}$ wavelength of maximum absorbance. 
Besides flavonols, other flavonoids in UAE-OPT extract corresponded to anthocyanins that were eluted from $7.6 \mathrm{~min}$ to $9.7 \mathrm{~min}$ (Peaks 6-8). Note that, in general, anthocyanins are preferred detected as $[\mathrm{M}]^{+}$in ESI in the positive mode, while typically they show [M-2H] ${ }^{-}$in the negative mode [47], as represented in Table 4. Overall, according to UV-Vis and $\mathrm{MS}^{\mathrm{n}}$ spectral data, these compounds were assigned to delphinidin, petunin and malvidin derivatives. In more detail, the compound in Peak 6 exhibiting a $[\mathrm{M}-2 \mathrm{H}]^{-}$at $m / z 463$ and a base peak $\mathrm{MS}^{2}$ fragment ion at $m / z 301(-162 \mathrm{Da})$ was assigned to delphinidin-O-hexoside by comparison with data reported in the literature [48-50]. In turn, petunidin- $O$-hexoside and a petunidin- $O$-hexoside derivative were eluted in Peaks 7 and 8 , respectively. The first showed a $[\mathrm{M}-2 \mathrm{H}]^{-}$at $m / z 477$ and a main $\mathrm{MS}^{2}$ fragment ions at $m / z$ 315/314 [48-50] while ions corresponding to petunidin-O-hexoside and its hydrated form (at $\mathrm{m} / \mathrm{z} 477$ and $\mathrm{m} / \mathrm{z} 495$, respectively) were predominant in $\mathrm{MS}^{2}$ spectrum of the latter compound. The petunidin-O-hexoside derivative was co-eluted with malvidin-O-hexoside $\left([\mathrm{M}-2 \mathrm{H}]^{-}\right.$at $\left.m / z 477 \rightarrow 329\right)$. Note that, except for petunidin-O-hexoside, hexosides of delphinidin, petunin and malvidin have already been described in distinct organs of $M$. communis, including pericarp [14,30,31,51,52].

Several non-flavonoid compounds could also be observed in UEA-OPT extract, including caffeoyl hexoside, gallic acid and galloyl derivatives. The first $\left([\mathrm{M}-\mathrm{H}]^{-}\right.$at $m / z 341 \rightarrow 179$, eluted in Peak 1$)$ was the only hydroxycinnamic acid found in the extract. Gallic acid ([M-H $]^{-}$at $m / z 169 \rightarrow 125$, eluted in Peak 4$)$, has been described in the literature for extracts obtained from the pericarp [16] berries [16,30] and leaves [38,52].

Regarding galloyl derivatives (typical $\mathrm{UV}_{\max }$ at 273-276 nm), these enclosed esters of monoor di-galloyl groups with a hexose or quinic acid unit, or even with myrtucommulone-type groups. In detail, the compound eluted in Peak 2 with a $[\mathrm{M}-\mathrm{H}]^{-}$at $\mathrm{m} / \mathrm{z} 331$ and corresponding fragments at $m / z$ 271, 169, 241, 211, 193 and 125, was assigned to a galloyl hexoside [53], presumably galloyl-3-O- $\beta$-D-galactoside-6-O-gallate, since this latter has been previously reported in $M$. communis leaves [2,38]. Besides, two isomers of galloyl quinic acid ([M-H] $]^{-}$at $\left.m / z 343 \rightarrow 191,169,125\right)$ could be found in Peaks 3 and 5, while a digalloyl hexoside $\left([\mathrm{M}-\mathrm{H}]^{-}\right.$at $\left.m / z 483 \rightarrow 271,331,313,439,193,169\right)$ and digalloyl quinic acid ([M-H] $]^{-}$at $\left.m / z 495 \rightarrow 343,325,191,169\right)$ were detected as co-eluted compounds in Peak 6. All these galloyl derivatives have been previously detected in M. communis leaves [35,38,52].

Moreover, four gallomyrtucommulone-type derivatives were found in UAE-OPT extract. All these compounds showed a $\mathrm{UV}_{\max }$ at $276 \mathrm{~nm}$, and similar fragment ions in $\mathrm{MS}^{\mathrm{n}}$ spectra, including ions at $m / z$ 331, 313, 271 and 211, which are typically formed in galloylhexoside [43]. Indeed, the ion at $\mathrm{m} / \mathrm{z} 331$ correspond to the galloyl hexoside moiety, while ions at $\mathrm{m} / \mathrm{z} 271$ and $\mathrm{m} / \mathrm{z} 211$ result from the cross-ring fragmentation of the hexose unit in the galloyl hexoside moiety and that at $m / z 313$ can be formed due to the loss of water molecule from the latter. Among these compounds, those eluted in Peaks 20 and $21\left([\mathrm{M}-\mathrm{H}]^{-}\right.$at $m / z 583$ and 567, respectively) were assigned to gallomyrtucommulone $\mathrm{F}$ and gallomyrtucommulone $\mathrm{C}$, in accordance to previous data reported in $M$. communis leaves [36]. Besides these two compounds, the extract also contained two isomeric unidentified gallomyrtucommulone-type derivatives (MW $468 \mathrm{Da}$ ) that presumably vary in their acyl chain regarding those previously identified.

\section{Conclusions}

The response surface methodology was successfully employed to optimize total phenolic extraction yield from dried $M$. communis pericarp by non-conventional solvent extraction process, namely using UAE. As compared to MAE and CSE extractions, the proposed UAE method allowed a higher phenolic recovery yield and antioxidant activity with a short working time and a lower solvent consumption. The quantification of the amounts of phenolic compounds in the three types of extract complemented with PCA analysis also allowed concluding that the $M$. communis pericarp extract obtained under optimal UAE experimental conditions contained higher levels of flavonoids, tannins and anthocyanin than the remaining extracts and, particularly, the latter phenolic components could be correlated to its antioxidant activity. According to UHPLC-DAD-ESI-MSn analysis, flavonols, particularly myricetin-O-hexoside and myricetin-O-deoxyhexoside, were the prevalent phenolic components of UAE-OPT. 
Author Contributions: N.B.-M. performed the experiments (extraction, optimization and quantification of phenolics and antioxidant activity), analyzed the data and wrote the original draft; L.B.-M. contributed to conceptualization, supervision, data curation, and writing-review and editing; K.M. conceptualized and supervised the research; A.M.S.S. contributed resources and performed writing-review and editing; S.D. contributed to the methodology; S.O.-B. contributed to the investigation; S.M.C. contributed to the supervision, data curation and writing-review and editing.

Funding: Foundation for Science and Technology (FCT), the European Union, the National Strategic Reference Framework (QREN), the European Regional Development Fund (FEDER), and Operational Programme Competitiveness Factors (COMPETE), for funding the Organic Chemistry Research Unit (QOPNA) (FCT UID/QUI/00062/2019), through national funds and where applicable co-financed by the FEDER, within the PT2020 Partnership Agreement. Project AgroForWealth (CENTRO-01-0145-FEDER-000001), funded by Centro2020, through FEDER and PT2020, financed the research contract of Susana M. Cardoso.

Conflicts of Interest: The authors have declared no conflict of interest.

\section{References}

1. Nuvoli, F.; Spanu, D. Analisie prospettive economiche dell'utilizzazionze industriale del mirto. Riv. Ital. EPPOS 1996, 12, 231-236. [CrossRef]

2. Sumbul, S.; Ahmad, M.A.; Asif, M.; Akhtar, M.; Saud, I. Physicochemical and phytochemical standardization of berries of Myrtus communis Linn. J. Pharm. Bioall. Sci. 2012, 4, 322-326. [CrossRef]

3. Messaoud, C.; Boussaid, M. Myrtus communis berry color morphs: A comparative analysis of essential oils, fatty acids, phenolic compounds, and antioxidant activities. Chem. Biodivers. 2011, 8, 300-310. [CrossRef]

4. Liu, R.H. Health benefits of fruit and vegetables are from additive and synergistic combinations of phytochemicals. Am. J. Clin. Nutr. 2003, 78, 517S-520S. [CrossRef]

5. Dahmoune, F.; Boulekbache, L.; Moussi, K.; Aoun, O.; Spigno, G.; Madani, K. Valorization of Citrus limon residues for the recovery of antioxidants: Evaluation and optimization of microwave and ultrasound application to solvent extraction. Ind. Crops Prod. 2013, 50, 77-87. [CrossRef]

6. Đorđević, T.; Antov, M. Ultrasound assisted extraction in aqueous two-phase system for the integrated extraction and separation of antioxidants from wheat chaff. Sep. Purif. Technol. 2017, 182, 52-58. [CrossRef]

7. De Castro, M.D.L.; García-Ayuso, L.E. Soxhlet extraction of solid materials: An outdated technique with a promising innovative future. Anal. Chim. Acta 1998, 369, 1-10. [CrossRef]

8. Chemat, F.; Rombaut, N.; Sicaire, A.-G.; Meullemiestre, A.; Fabiano-Tixier, A.-S.; Abert-Vian, M. Ultrasound assisted extraction of food and natural products. Mechanisms, techniques, combinations, protocols and applications. A review. Ultrason. Sonochem. 2017, 34, 540-560. [CrossRef]

9. Živković, J.; Šavikin, K.; Janković, T.; Ćujić, N.; Menković, N. Optimization of ultrasound-assisted extraction of polyphenolic compounds from pomegranate peel using response surface methodology. Sep. Purif. Technol. 2018, 194, 40-47. [CrossRef]

10. Jacotet-Navarro, M.; Rombaut, N.; Deslis, S.; Fabiano-Tixier, A.-S.; Pierre, F.-X.; Bily, A.; Chemat, F. Towards a "dry" bio-refinery without solvents or added water using microwaves and ultrasound for total valorization of fruit and vegetable by-products. Green Chem. 2016, 18, 3106-3115. [CrossRef]

11. Zu, G.; Zhang, R.; Yang, L.; Ma, C.; Zu, Y.; Wang, W.; Zhao, C. Ultrasound-assisted extraction of carnosic acid and rosmarinic acid using ionic liquid solution from Rosmarinus officinalis. Int. J. Mol. Sci. 2012, 13, 11027-11043. [CrossRef] [PubMed]

12. Yan, Y.-L.; Yu, C.-H.; Chen, J.; Li, X.-X.; Wang, W.; Li, S.-Q. Ultrasonic-assisted extraction optimized by response surface methodology, chemical composition and antioxidant activity of polysaccharides from Tremella mesenterica. Carbohydr. Polym. 2011, 83, 217-224. [CrossRef]

13. Bezerra, M.A.; Santelli, R.E.; Oliveira, E.P.; Villar, L.S.; Escaleira, L.A. Response surface methodology (RSM) as a tool for optimization in analytical chemistry. Talanta 2008, 76, 965-977. [CrossRef] [PubMed]

14. Montoro, P.; Tuberoso, C.I.G.; Piacente, S.; Perrone, A.; De Feo, V.; Cabras, P.; Pizza, C. Stability and antioxidant activity of polyphenols in extracts of Myrtus communis L. berries used for the preparation of myrtle liqueur. J. Pharm. Biomed. 2006, 41, 1614-1619. [CrossRef] [PubMed]

15. Amensour, M.; Sendra, E.; Abrini, J.; Bouhdid, S.; Pérez-Alvarez, J.A.; Fernández-López, J. Total phenolic content and antioxidant activity of myrtle (Myrtus communis) extracts. Nat. Prod. Commun. 2009, 4, 819-824. [CrossRef] [PubMed] 
16. Tuberoso, C.I.G.; Rosa, A.; Bifulco, E.; Melis, M.P.; Atzeri, A.; Pirisi, F.M.; Dessì, M.A. Chemical composition and antioxidant activities of Myrtus communis L. berries extracts. Food Chem. 2010, 123, 1242-1251. [CrossRef]

17. Jovanović, A.A.; Đorđević, V.B.; Zdunić, G.M.; Pljevljakušić, D.S.; Šavikin, K.P.; Gođevac, D.M.; Bugarski, B.M. Optimization of the extraction process of polyphenols from Thymus serpyllum L. herb using maceration, heat-and ultrasound-assisted techniques. Sep. Purif. Technol. 2017, 179, 369-380. [CrossRef]

18. Bouaoudia-Madi, N.; Boulekbache-Makhlouf, L.; Kadri, N.; Dahmoune, F.; Remini, H.; Dairi, S.; Oukhmanou-Bensidhoum, S.; Madani, K. Phytochemical analysis of Myrtus communis plant: Conventional versus microwave assisted-extraction procedures. J. Complement. Integr. Med. 2017, 14. [CrossRef]

19. Benmeziane, A.; Boulekbache-Makhlouf, L.; Mapelli-Brahm, P.; Khaled Khodja, N.; Remini, H.; Madani, K.; Meléndez-Martínez, A.J. Extraction of carotenoids from cantaloupe waste and determination of its mineral composition. Food Res. Int. 2018, 111, 391-398. [CrossRef]

20. George, S.; Brat, P.; Alter, P.; Amiot, M.J. Rapid Determination of Polyphenols and Vitamin C in Plant-Derived Products. J. Agric. Food Chem. 2005, 53, 1370-1373. [CrossRef]

21. Quettier-Deleu, C.; Gressier, B.; Vasseur, J.; Dine, T.; Brunet, C.; Luyckx, M.; Cazin, M.; Cazin, J.-C.; Bailleul, F.; Trotin, F. Phenolic compounds and antioxidant activities of buckwheat (Fagopyrum esculentum Moench) hulls and flour. J. Ethnopharmacol. 2000, 72, 35-42. [CrossRef]

22. Cheok, C.Y.; China, N.L.; Yusof, Y.A.; Talib, R.A.; Law, C.L. Optimization of total monomeric anthocyanin (TMA) and total phenolic content (TPC) extractions from mangosteen (Garcinia mangostana Linn.) hull using ultrasonic treatments. Ind. Crops Prod. 2013, 50,1-7. [CrossRef]

23. Wannes, W.A.; Mhamdi, B.; Sriti, J.; Jemia, M.B.; Ouchikh, O.; Hamdaoui, G.; Kchouk, M.E.; Marzouk, B. Antioxidant activities of the essential oils and methanol extracts from myrtle (Myrtus communis var. italica L.) leaf, stem and flower. Food Chem. Toxicol. 2010, 48, 1362-1370. [CrossRef] [PubMed]

24. Zou, Y.; Lu, Y.; Wei, D. Antioxidant activity of a flavonoid-rich extract of Hypericum perforatum L. in vitro. J. Agric. Food Chem. 2004, 52, 5032-5039. [CrossRef]

25. Pereira, O.R.; Catarino, M.D.; Afonso, A.F.; Silva, A.M.S.; Cardoso, S.M. Salvia elegans, Salvia greggii and Salvia officinalis Decoctions: Antioxidant Activities and Inhibition of Carbohydrate and Lipid Metabolic Enzymes. Molecules 2018, 23, 3169. [CrossRef] [PubMed]

26. Jacotet-Navarro, M.; Rombaut, N.; Fabiano-Tixier, A.-S.; Danguien, M.; Bily, A.; Chemat, F. Ultrasound versus microwave as green processes for extraction of rosmarinic, carnosic and ursolic acids from rosemary. Ultrason. Sonochem. 2015, 27, 102-109. [CrossRef] [PubMed]

27. Dahmoune, F.; Moussi, K.; Remini, H.; Belbahi, A.; Aoun, O.; Spigno, G.; Madani, K. Optimization of Ultrasound-Assisted Extraction of Phenolic Compounds from Citrus sinensis L. Peels using Response Surface Methodology. Chem. Eng. Trans. 2014, 37, 889-894. [CrossRef]

28. Dahmoune, F.; Spigno, G.; Moussi, K.; Remini, H.; Cherbal, A.; Madani, K. Pistacia lentiscus leaves as a source of phenolic compounds: Microwave-assisted extraction optimized and compared with ultrasound-assisted and conventional solvent extraction. Ind. Crops Prod. 2014, 61, 31-40. [CrossRef]

29. Ghafoor, K.; Choi, Y.H.; Jeon, J.Y.; Jo, I.H. Optimization of ultrasound-assisted extraction of phenolic compounds, antioxidants, and anthocyanins from grape (Vitis vinifera) seeds. J. Agric. Food Chem. 2009, 57, 4988-4994. [CrossRef] [PubMed]

30. Wannes, W.A.; Marzouk, B. Differences between myrtle fruit parts (Myrtus communis var. italica) in phenolics and antioxidant contents. J. Food Biochem. 2013, 37, 585-594. [CrossRef]

31. Pereira, P.; Cebola, M.-J.; Oliveira, M.C.; Bernardo-Gil, M.G. Supercritical fluid extraction vs conventional extraction of myrtle leaves and berries: Comparison of antioxidant activity and identification of bioactive compounds. J. Supercrit. Fluid 2016, 113, 1-9. [CrossRef]

32. Romani, A.; Pinelli, P.; Mulinacci, N.; Vincieri, F.; Tattini, M. Identification and quantitation of polyphenols in leaves of Myrtus communis L. Chromatographia 1999, 49, 17-20. [CrossRef]

33. Boldbaatar, D.; El-Seedi, H.R.; Findakly, M.; Jabri, S.; Javzan, B.; Choidash, B.; Göransson, U.; Hellman, B. Antigenotoxic and antioxidant effects of the Mongolian medicinal plant Leptopyrum fumarioides (L): An in vitro study. J. Ethnopharmacol. 2014, 155, 599-606. [CrossRef] [PubMed]

34. Romani, A.; Coinu, R.; Carta, S.; Pinelli, P.; Galardi, C.; Vincieri, F.F.; Franconi, F. Evaluation of antioxidant effect of different extracts of Myrtus communis L. Free Radic. Res. 2004, 38, 97-103. [CrossRef] [PubMed]

35. Romani, A.; Campo, M.; Pinelli, P. HPLC/DAD/ESI-MS analyses and anti-radical activity of hydrolyzable tannins from different vegetal species. Food Chem. 2012, 130, 214-221. [CrossRef] 
36. Taamalli, A.; Iswaldi, I.; Arráez-Román, D.; Segura-Carretero, A.; Fernández-Gutiérrez, A.; Zarrouk, M. UPLC-QTOF/MS for a rapid characterisation of phenolic compounds from leaves of Myrtus communis L. Phytochem. Anal. 2014, 25, 89-96. [CrossRef] [PubMed]

37. Hasdemir, B.; Yaşa, H.; Onar, H.Ç.; Yusufoğlu, A.S. Investigation of essential oil composition, polyphenol content, and antioxidant activity of Myrtus communis L. from Turkey. JOTCSA 2016, 3, 427-438. [CrossRef]

38. Yoshimura, M.; Amakura, Y.; Tokuhara, M.; Yoshida, T. Polyphenolic compounds isolated from the leaves of Myrtus communis. J. Nat. Med. 2008, 62, 366-368. [CrossRef]

39. Boulekbache-Makhlouf, L.; Medouni, L.; Medouni-Adrar, S.; Arkoub, L.; Madani, K. Effect of solvents extraction on phenolic content and antioxidant activity of the byproduct of eggplant. Ind. Crops Prod. 2013, 49, 668-674. [CrossRef]

40. Saldanha, L.L.; Vilegas, W.; Dokkedal, A.L. Characterization of flavonoids and phenolic acids in Myrcia bella cambess. Using FIA-ESI-IT-MSn and HPLC-PAD-ESI-IT-MS combined with NMR. Molecules 2013, 18, 8402-8416. [CrossRef]

41. Sobeh, M.; ElHawary, E.; Peixoto, H.; Labib, R.M.; Handoussa, H.; Swilam, N.; El-Khatib, A.H.; Sharapov, F.; Mohamed, T.; Krstin, S. Identification of phenolic secondary metabolites from Schotia brachypetala Sond. (Fabaceae) and demonstration of their antioxidant activities in Caenorhabditis elegans. PeerJ 2016, 4, e2404. [CrossRef] [PubMed]

42. Cadahía, E.; Conde, E.; García-Vallejo, M.; Fernández de Simón, B. High pressure liquid chromatographic analysis of polyphenols in leaves of Eucalyptus camaldulensis, E. globulus and E. rudis: Proanthocyanidins, ellagitannins and flavonol glycosides. Phytochem. Anal. 1997, 8, 78-83. [CrossRef]

43. Amakura, Y.; Yoshimura, M.; Sugimoto, N.; Yamazaki, T.; Yoshida, T. Marker constituents of the natural antioxidant Eucalyptus leaf extract for the evaluation of food additives. Biosci. Biotechnol. Biochem. 2009, 73, 1060-1065. [CrossRef]

44. Okamura, H.; Mimura, A.; Niwano, M.; Takahara, Y.; Yasuda, H.; Yoshida, H. Two acylated flavonol glycosides from Eucalyptus rostrata. Phytochemistry 1993, 33, 512-514. [CrossRef]

45. Cascaes, M.; Guilhon, G.; Andrade, E.; Zoghbi, M.; Santos, L. Constituents and pharmacological activities of Myrcia (Myrtaceae): A review of an aromatic and medicinal group of plants. Int. J. Mol. Sci. 2015, 16, 23881-23904. [CrossRef]

46. Hussein, S.A.; Hashem, A.N.; Seliem, M.A.; Lindequist, U.; Nawwar, M.A. Polyoxygenated flavonoids from Eugenia edulis. Phytochemistry 2003, 64, 883-889. [CrossRef]

47. Barboni, T.; Venturini, N.; Paolini, J.; Desjobert, J.-M.; Chiaramonti, N.; Costa, J. Characterisation of volatiles and polyphenols for quality assessment of alcoholic beverages prepared from Corsican Myrtus communis berries. Food Chem. 2010, 122, 1304-1312. [CrossRef]

48. Bochi, V.C.; Godoy, H.T.; Giusti, M.M. Anthocyanin and other phenolic compounds in Ceylon gooseberry (Dovyalis hebecarpa) fruits. Food Chem. 2015, 176, 234-243. [CrossRef]

49. Dias, T.; Bronze, M.R.; Houghton, P.J.; Mota-Filipe, H.; Paulo, A. The flavonoid-rich fraction of Coreopsis tinctoria promotes glucose tolerance regain through pancreatic function recovery in streptozotocin-induced glucose-intolerant rats. J. Ethnopharmacol. 2010, 132, 483-490. [CrossRef]

50. Lopes-Lutz, D.; Dettmann, J.; Nimalaratne, C.; Schieber, A. Characterization and quantification of polyphenols in Amazon grape (Pourouma cecropiifolia Martius). Molecules 2010, 15, 8543-8552. [CrossRef]

51. Scorrano, S.; Lazzoi, M.R.; Mergola, L.; Di Bello, M.P.; Del Sole, R.; Vasapollo, G. Anthocyanins Profile by Q-TOF LC/MS in Myrtus communis Berries from Salento Area. Food Anal. Methods 2017, 10, 2404-2411. [CrossRef]

52. Romani, A.; Pinelli, P.; Galardi, C.; Mulinacci, N.; Tattini, M. Identification and quantification of galloyl derivatives, flavonoid glycosides and anthocyanins in leaves of Pistacia lentiscus L. Phytochem. Anal. 2002, 13, 79-86. [CrossRef] [PubMed]

53. Abu-Reidah, I.M.; Ali-Shtayeh, M.S.; Jamous, R.M.; Arráez-Román, D.; Segura-Carretero, A. HPLC-DADESI-MS/MS screening of bioactive components from Rhus coriaria L. (Sumac) fruits. Food Chem. 2015, 166, 179-191. [CrossRef] [PubMed]

(C) 2019 by the authors. Licensee MDPI, Basel, Switzerland. This article is an open access article distributed under the terms and conditions of the Creative Commons Attribution (CC BY) license (http://creativecommons.org/licenses/by/4.0/). 